\title{
Anthology of Polish Animated Film DVD
}

By Jan Uhde

Fall 2007 Issue of KINEMA

THE PUBLICATION of the Anthology of Polish animation set was without doubt one of the DVD events of 2007. Covering the production of the last fifty years, it offers a collection of the crème de la crème of Polish animation, with twenty-eight shorts by twenty filmmakers, from Jan Lenica and Walerian Borowczyk (The House), Piotr Dumala (Gentle Spirit) to Zbigniew Rybczynski (Tango).

This long-awaited anthology is the first attempt to open the window on the world of the Poland's legendary animation, until recently out of reach to most audiences outside Poland. Content aside, the image quality of the films is very good, despite the disparate sources and varying age of the prints. Moreover, the boxed set's design and aesthetic quality are exemplary. One can only hope this DVD will provide inspiration for similar efforts that would help unlock more from the treasury of Polish animation of the last half-century to international audiences.

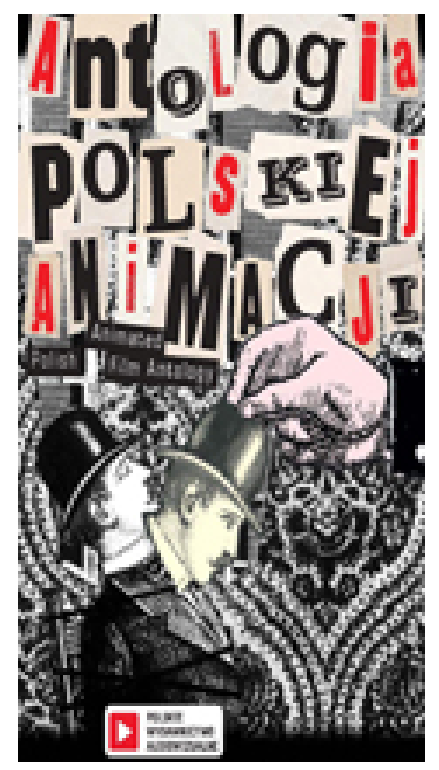

Figure 1: ANTHOLOGY OF POLISH ANIMATED FILM DVD ฯ (2-disc set, various directors, 1958-2005), PAL, Region 0, DVD-9, 222min. Booklet (50pp.) Sound: Polish. đ Subtitles: English and French. Polskie Wydawnictwo Audiowizualne (PWA). ब PLN 39.00 at PWA Online (USD 15.50).

\section{Author Information}

Jan UHDE is Professor Emer. (Film Studies) at the University of Waterloo, Ontario, Canada. Born in Brno, Czech Republic. Graduated (MA) from the Faculty of Arts, Masaryk University, Brno; PhD received at the University of Waterloo, Ontario, Canada. He taught at the University of Waterloo (1970-2012) where he founded a General and Honours BA program in Film Studies at the Department of Fine Arts.

Publications: Latent Images: Film in Singapore Second edition, with Yvonne Ng Uhde (Ridge Books, National University Press of Singapore, 2010); Latent Images: Film in Singapore, with Yvonne Ng Uhde (Oxford University Press, 2000); Latent Images: Film in Singapore CD-ROM (2003, co-author); Vision and Persistence: Twenty Years of the Ontario Film Institute (University of Waterloo Press, 1990) and Ontario Film Institute Programming Activities Index 1969-1989 (Toronto: Ontario Science Centre, 1990). He co-edited the Place in Space: Human Culture in Landscape (Proceedings from the Second International Conference of 
the Working Group "Culture and Landscape" of the International Association of Landscape Ecology, Pudoc Scientific Publishers, Wageningen, Holland, 1993). Jan Uhde has published articles and reviews in several countries (including Canada, USA, Germany, Italy), participated in international juries at film festivals and presented papers at international conferences in North America and Europe. In 1998/99, he was a visiting researcher at the School for Film and Media Studies, Ngee Ann Polytechnic, Singapore.

His professional and research interests focus on Singapore cinema; the identification and distancing mechanisms of the film viewer; the non-authored modifications and manipulation of films; and specific aspects of film history, including the Central European cinema.

He founded KINEMA in 1993. 